\title{
Intelligent Supply Chain Management
}

\author{
Mohammad Zubair Khan ${ }^{1}$, Omar Al-Mushayt ${ }^{1}$, Jahangir Alam ${ }^{2}$, Jorair Ahmad ${ }^{1}$ \\ ${ }^{1}$ Faculty of Computer Science and Information System, University of Jizan, Jizan, Kingdom of Saudi Arabia; ${ }^{2}$ University Women’s \\ Polytechnic, Faculty of Engineering and Technology, Aligarh Muslim University, Aligarh, India. \\ Email: Zubair.762001@gmail.com,oalmushayt@yahoo.com, Jahangir.uk786@yahoo.co.uk
}

Received December 27 ${ }^{\text {th }}$, 2009; revised January 31 ${ }^{\text {st }}$ 2010; accepted February $5^{\text {th }}, 2010$.

\begin{abstract}
Fuzzy Logic is used to derive the optimal inventory policies in the Supply Chain (SC) numbers. We examine the performance of the optimal inventory policies by cutting the costs and increasing the supply chain management efficiency. The proposed inventory policy uses multi-agent and Fuzzy logic, and provides managerial insights on the impact of the decision making in all the SC numbers. In particular, we focus on the way in which our agent purchases components using a mixed procurement strategy (combining long and short term planning) and how it sets its prices according to the prevailing market conditions and its own inventory level (because this adaptivity and flexibility are key to its success). In modern global market, one of the most important issues of the supply chain (SC) management is to satisfy changing customer demands and enterprises should enhance the long-term advantage through the optimal inventory control. In this paper an intelligent multi-agent system to simulate supply chain management has been developed.
\end{abstract}

Keywords: SCM Supply Chain Management, Customer Agent, RFQ, Component Agent

\section{Background and Introduction}

\subsection{Supply Chain Management}

Supply chains encompass the companies and the business activities needed to design, make, deliver, and use a product or service. Businesses depend on their supply chains to provide them with what they need to survive and thrive [1-3]. Every business fits into one or more supply chains and has a role to play in each of them $[3,4]$. A multiechelon supply chain is illustrated in Figure 1. It includes different types of flows i.e. financial flow, Information flow and material flow. Third party logistics (3PL) services providers (3PL is an organization that manages and executes a particular logistics function, using its own assets and resources, on behalf of another company.) handle the inbound and outbound logistics for the shipper (The person or company who is usually the supplier or owner of commodities shipped). The inbound logistics take care of the material management while the outbound logistics deal with physical distribution of final products. The term "supply chain management" arose in the late 1980s and came into widespread use in the 1990s. Prior to that time, businesses used terms such as "logistics" and "operations management" instead. Some definitions of a supply chain are offered below:

- "A supply chain is the alignment of firms that bring products or services to market."-Lambert, Stock, and Ellram (1998).
- "A supply chain consists of all stages involved, directly or indirectly, in fulfilling a customer request. The supply chain not only includes the manufacturer and suppliers, but also transporters, warehouses, retailers, and customers themselves."-Chopra and Meindl (2001).

- "A supply chain is a network of facilities and distribution options that performs the functions of procurement of materials, transformation of these materials into intermediate and finished products, and the distribution of these finished products to customers."-Ganeshan and Harrison (1995).

Master strategist and a skillful general Napoleon once remarked, "An army marches on its stomach." Which holds true in business, as it moves on physical flow of materials, another saying that goes is also valid for the business, "Amateurs talk strategy and professionals talk logistics" [5-7].

Thus, we can say that Supply chain management is a set of approaches used to efficiently integrate suppliers, manufacturers, warehouses, and customers so that merchandise is produced and distributed at the right quantities, to the right locations, and at the right time in order to minimize system wise costs while satisfying servicelevel requirements.

Supply chain management (SCM) is the task that moves in a process from supplier to manufacturer to wholesaler to retailer to consumer $[1,4]$. Supply chain management involves coordinating and integrating these 


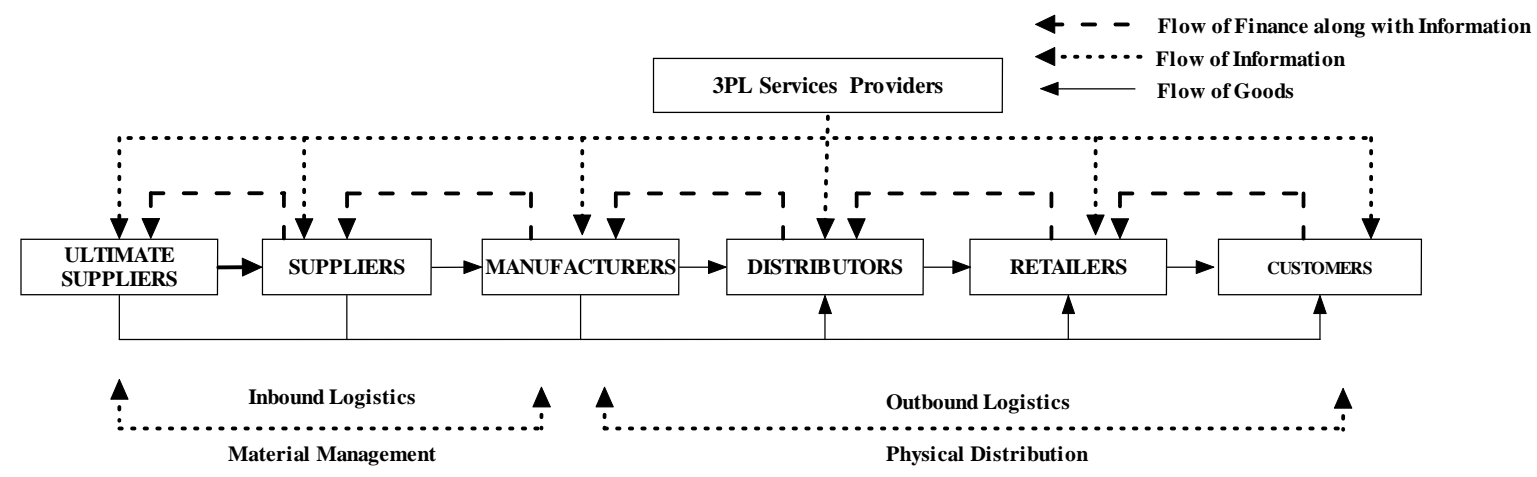

Figure 1. The supply chain process

flows both within and among companies [2,8]. It is said that the ultimate goal of any effective supply chain management system is to reduce inventory (with the assumption that products are available when needed).

Supply chain management flows can be divided into three main flows:

- The product flow

- The information flow

- The finances flow

The need of Supply chain Management in today's scenario is:

- Millions of dollars at stake!

- Excess Inventory costs

- Excess freight charges

- Lost sales/Stock outages

- Wasted time and energy

- Extra staff

- Listings/Delisting

- Customer dissatisfaction - privatization

- Capital costs

- Real Estate Costs

- $\quad$ Static and unresponsive SC policies

- Large inventories

- Unreliable deliveries

- Underperformance

\subsection{Fuzzy Logic}

Fuzzy logic is a form of multi-valued logic derived from fuzzy set theory to deal with reasoning that is approximate rather than precise. Just as in fuzzy set theory the set membership values can range (inclusively) between any values, in fuzzy logic the degree of truth of a statement can range between any values and is not constrained to the two truth values \{true, false as in classic predicate logic [1]. And when linguistic variables are used, these degrees may be managed by specific functions, as discussed below.

Fuzzy Set Theory defines Fuzzy Operators on Fuzzy Sets. The problem in applying this is that the appropriate Fuzzy Operator may not be known. For this reason, Fuzzy logic usually uses IF-THEN rules, or constructs that are equivalent, such as fuzzy associative matrices. Rules are usually expressed in the form: IF variable IS property THEN action.

For example, an extremely simple temperature regulator that uses a fan might look like this: If temperature IS very cold THEN stop fan. If temperature is cold THEN turn down fan. If temperature IS normal THEN maintain level. IF temperature IS hot THEN speed up fan. Notice there is no "ELSE". All of the rules are evaluated, because the temperature might be "cold" and "normal" at the same time to different degrees. This paper proposes a multi-agent system to simulate supply chain management using the concepts of fuzzy logic. The rest of the paper is organizes as follows-Section 2 presents the proposed model, Methodology adopted conducting the experiments and results so obtained have been discussed in Section 3. Section 4 concludes the paper.

\section{Proposed Model}

The proposed SCM model has been depicted in Figure 2. In our model we are introducing the customer agent and Customer RFQ (Request for Quantities). The customer agent receives customer RFQ requesting a quantity of a particular commodity for delivery on a specified day. The customer agent is the key component while component agent is responsible for dealing with the component suppliers and aims to ensure that there are always sufficient components in stock to address the customers' changing demand for finished products.

In our model we propose customer agent only and leave the component agent for future studies.

\subsection{The Customer Agent}

The customer agent is the key component in our model (because we believe that offering the appropriate price at the right time is vital for success). If the price is too low, the agent will receive a low profit and if it is too high it will fail to win any orders (because the natural tendency of customers is to always choose the lowest offer price among those they receive). Given this, the key challenges are to determine which customer RFQ to bid for and at 


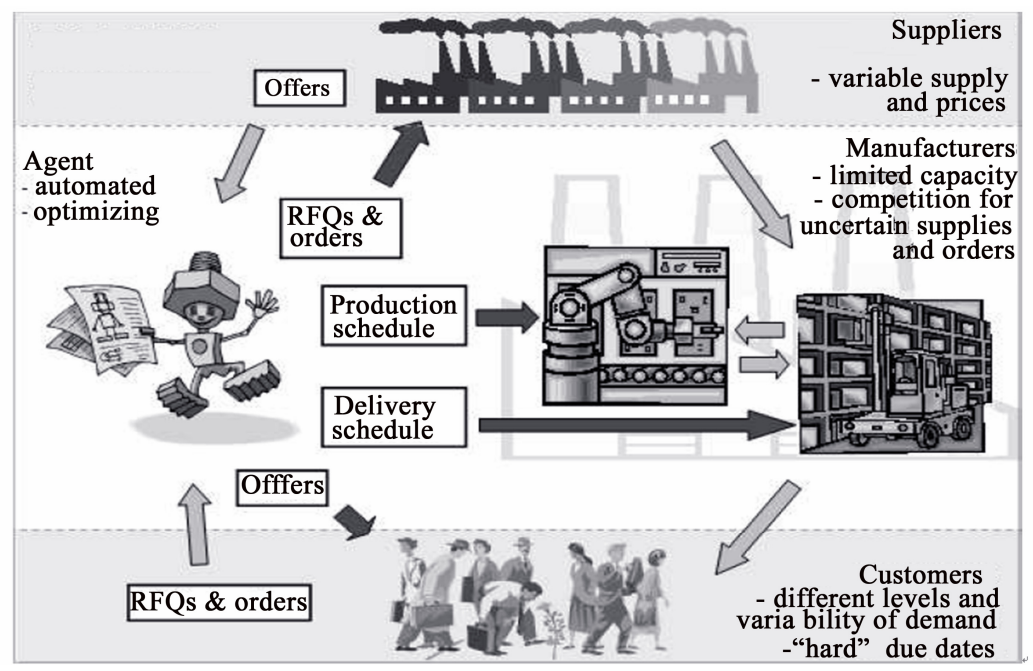

Figure 2. The SCM model

what price. To achieve this, we use fuzzy reasoning $[9,10]$ to determine how to set prices according to the agent's inventory level, the market demand and the time into consideration.

\subsection{Choosing Customer RFQ's}

The customer agent receives customer RFQs requesting a quantity of a particular commodity for delivery on a specified day [2,8,11]. When selecting which RFQs to respond to, Our ISCM rates them according to the potential profit that they may bring and according to the inventory it holds. The latter inventory driven strategy offers customers commodity according to what is currently available and also what can be produced given the delivery date of pending components orders. In more detail, suppose a customer RFQ is represented as a tuple (i, q, pres, cpenalty, pbase), where $i$ is the type of commodity the customer wants, $q>0$ is the quantity, pres $>0$ is the reservation price (maximum it will pay), cpenalty $>0$ is the fine paid if the computers are not delivered on time, and ddue is the desired delivery date. On each day, the customer agent receives a bundle of such RFQs and sorts them in the decreasing order of the profit margin of the type of commodity requested. Here pbase is the cost of buying components (sum of the buying price for each component). The intuition is that the agent will first serve customers with high profit margins and low penalties. This is because the higher the pres, the more profit will be made (compared to selling the same product to a customer with a low pres). At the same time, the agent also wants to avoid getting high penalty orders because of the inherent uncertainties that exist in the scenario.

\section{Profit Margin = Pres-Pbase- $($ cpenalty/q)}

\section{Methodology}

We are applying the Fuzzy logic if-else algorithm using the following rules and simulated it using available data. Here we define fuzzy rules and then revisited the rules for our goal.

\subsection{Fuzzy Rules for Calculating Offer Prices}

- $\quad \mathrm{R} 1$ : if $\mathrm{D}$ is high and $\mathrm{I}$ is low then $\mathrm{r} 1$ is very-big

- R2: if $\mathrm{D}$ is medium and $\mathrm{I}$ is high then $\mathrm{r} 2$ is very-medium

- R3: if $\mathrm{D}$ is low and $\mathrm{I}$ is high then $\mathrm{r} 3$ is small

\subsection{Fuzzy Rules Revisited}

- If $\mathrm{D}$ is high $\mathrm{I}$ is High $\mathrm{E}$ is far then $\mathrm{r} 1^{`}$ is big.

- If $\mathrm{D}$ is high $\mathrm{I}$ is High $\mathrm{E}$ is in between then $\mathrm{r} 2$ ' is big.

- If $\mathrm{D}$ is high I is High $\mathrm{E}$ is near then $\mathrm{r} 3$ is big.

\subsection{The Component Agent}

The component agent is responsible for dealing with the component suppliers and aims to ensure that there are always sufficient components in stock to address the customers' changing demand for finished products. In doing so, it addresses a challenge that is common to all supply chains facing dynamically changing customer demand. That is, it must procure components at a low cost, whilst simultaneously maintaining a minimal component inventory in order to reduce the daily storage cost and also the possibility of being left with redundant stock if customer demands changes.

\section{Types of procurements}

- Far future procurement

- Near Future Procurement

\subsubsection{Far Future Procurement}

Of the two strategies, the far future procurement one is the simpler. For this, the agent assumes that in the far future, there will be a daily minimum need, and thus checks whether there is sufficient current and pending 
component inventory to meet this need. If not, it submits an RFQ for a fixed amount to the relevant supplier, requesting delivery on the date at which the predicted inventory falls below the daily minimum need.

\subsubsection{Near Future Procurement}

The near future procurement strategy is more complex. It consists of two elements, a daily demand predictor that predicts the future demand of components, and a market tracker that generates the RFQs to be sent to the suppliers, both to order actual components required and to test the market to discern the most profitable order lead time and set appropriate reserve price

\subsection{Demand Predictor}

As described above, the agent buys components for the near future based on a prediction of customer demand. Now, according to the game specification, the number of RFQs that each agent receives from the customers is described by three independent random walks; one for each market segment (finished products are classified into three such segments: high, mid and low range). In more detail, the number of RFQs that an agent receives, within a single market segment, on day $\mathrm{d}$ is denoted by $\mathrm{Nd}$, and is drawn from a Poisson distribution whose expected value is given by the parameter, $\mathrm{Qd}$. Thus, for each market segment,

$$
N d=\operatorname{Poisson}(Q d)
$$

Having predicted the number of RFQs that will be received, within each market segment, on each day within the near future, the agent then calculates the expected daily usage of each component type (Did).

\subsection{Price Tracker}

The price tracker acts to maintain an estimate of the current market price of the components. Due to the behaviors of the competing agents, this market price depends on the due date with which components are requested. For example, if the competing agents are ordering components with very short lead times, then the supplier will have little spare capacity, and thus, the corresponding offer prices that the agent receives will be greater than those of orders with long lead times.

\subsection{Factory Agent}

One of the main challenges for the factory agent is scheduling what to produce and when to produce it (i.e., how to allocate supply resources and factory time).

This strategy involves manufacturing commodities according to customer orders and satisfying orders with an earlier delivery date. Now, since the computers stored in the factory will be charged storage cost, each order will be delivered as soon as it is filled. The agent builds the commodity according to the customers' orders it has obtained (which has the advantage of ensuring that the factory always produces the needed computers on time). However, if on any day, there are still free factory assembling cycles available, and the numbers of finished PCs in stock are below a certain threshold, then the agent produces additional PCs of each kind uniformly (subject to the availability of components) in order to maximize the factory utilization. It is critical that this threshold is set appropriately; a high threshold will lead to excessive finished PC inventory, which may be hard to sell if demand is low.

\subsection{Simulated Results}

\begin{tabular}{|c|c|c|c|}
\hline $\begin{array}{c}\text { Profit } \\
\text { Margin }\end{array}$ & Inventory & $\begin{array}{c}\text { End of sea- } \\
\text { son }\end{array}$ & $\begin{array}{c}\text { Predictors } \\
\text { Decision }\end{array}$ \\
\hline High & High & Far & yes \\
\hline High & High & In Between & yes \\
\hline High & High & Near & yes \\
\hline High & Medium & Far & yes \\
\hline High & Medium & In Between & yes \\
\hline High & Medium & Near & no \\
\hline High & Low & Far & yes \\
\hline High & Low & In Between & no \\
\hline High & Low & Near & no \\
\hline Medium & High & Far & yes \\
\hline Medium & High & In Between & yes \\
\hline Medium & High & Near & yes \\
\hline Medium & Medium & Far & yes \\
\hline Medium & Medium & In Between & yes \\
\hline Medium & Medium & Near & no \\
\hline Medium & Low & Far & no \\
\hline Medium & Low & In Between & no \\
\hline Medium & Low & Near & no \\
\hline Low & High & Far & no \\
\hline Low & High & In Between & no \\
\hline Low & High & Near & yes \\
\hline Low & Medium & Far & no \\
\hline Low & Medium & In Between & no \\
\hline Low & Medium & Near & no \\
\hline Low & Low & Far & no \\
\hline Low & Low & In Between & no \\
\hline Low & Low & Near & no \\
\hline
\end{tabular}

\section{Conclusions}

This mixture of baseline and opportunistic purchasing behavior is a common strategy in this domain and the technology we develop for achieving this can be readily transferred. Second, we believe our pricing model technology will also be useful in real SCM applications where just undercutting competitors' prices can significantly improve profitability. Specifically, to apply our model in other domains, the designers of the rule base would need to adapt the fuzzy rules to reflect the factors that are most relevant. Now we believe that customer demand and inventory level are highly likely to be critical factors for almost all cases and thus these rules can remain unaltered.

By using different rule bases, different factors can easily be incorporated (as we did here, in order to handle the additional need to reduce inventory towards the end of the season). The purpose model also will use in this area 
focuses on the component agent. We would like to improve it so that it can adapt the quantity for far future and near future procurement automatically between the seasons according to the procurement behaviors employed by the opponents.

\section{REFERENCES}

[1] J. Collins, R. Arunachalam, et al., "The Supply Chain Management Game for the 2005 Trading Agent Competition,” Technical Report CMU-ISRI-04-139, School of Computer Science, Carnegie Mellon University, Pittsburgh, December 2004.

[2] S. D. Levi, P. Kaminsky and S. E. Levi, "Designing and Managing the Supply Chain,” McGraw-Hill, Illinois, 2000.

[3] D. Pardoe and P. Stone, “TacTex-03: A supply Chain Management Agent,” SIGecom Exchanges: Special Issue on Trading Agent Design and Analysis, Vol. 4, No. 3, 2004, pp. 19-28.

[4] K. Kumar, "Technology for Supporting Supply-Chain Management," Communications of the ACM, Vol. 44, No. 6, pp. 58-61, 2001.

[5] D. Pardoe and P. Stone, "Predictive Planning for Supply Chain Management," Proceedings of International Con- ference on Automated Planning and Scheduling, to appear.

[6] M. Sugeno, “An Introductory Survey of Fuzzy Control,” Information Sciences, Vol. 36, 1985, pp. 59-83.

[7] M. Wellman, J. Estelle, S. Singh, et al., "Strategic Interactions in a Supply Chain Game," Computational Intelligence, Vol. 21, No. 1, 2005, pp. 1-26.

[8] M. He, H. F. Leung and N. R. Jennings, “An ARTMAP Based Bidding Strategy for Autonomous Agents in Continuous Double Auctions," IEEE Transactions on Knowledge and Data Engineering, Vol. 15, No. 6, 2003, pp. 1345-1363.

[9] R. Arunachalam and N. Sadeh, "The Supply Chain Trading Agent Competition,” Electronic Commerce Research and Applications, Vol. 4, No. 1, 2005, pp. 63-81.

[10] J. Collins, R. Arunachalam, N. Sadeh, J. Ericsson, N. Finne and S. Janson, "The Supply Chain Management Trading Agent Competition,” Technical Report CMUISRI-04-139, Carnegie Mellon University, Pittsburgh, 2004.

[11] M. He, N. R. Jennings and H. Leung, "On Agent-Mediated Electronic Commerce," IEEE Transactions on Knowledge and Data Engineering, Vol. 15, No. 4, 2003, pp. 985-1003. 